\title{
Influência de métodos de debicagem e do tipo de bebedouro no desempenho e na qualidade dos ovos de codornas japonesas ${ }^{1}$
}

\author{
Christine Laganá2 ${ }^{2}$ Carla Cachoni Pizzolante ${ }^{2}$, Cristina Kimie Togashi², Sergio Kenji \\ Kakimoto², Érika Salgado Politi Braga Saldanha², Valdemir Álvares ${ }^{2}$
}

\author{
1 Iniciativa privada. \\ 2 Agência Paulista de Tecnologia dos Agronegócios - APTA Regional. Caixa Postal 01, 13910-000, Monte Alegre do Sul-SP.
}

RESUMO - Com o objetivo de avaliar o efeito da debicagem e do tipo de bebedouro sobre o desempenho produtivo de codornas japonesas, 672 fêmeas de codornas de um dia foram usadas em um delineamento inteiramente casualizado e distribuídas em um dos três tratamentos como não-debicagem; debicagem até $1 / 3$ dos bicos; e cauterização, com oito repetições de 28 aves na fase de cria. As aves foram debicadas aos 21 dias de idade e, no 35 dia, foram avaliados o ganho de peso, o consumo de ração, a conversão alimentar e a taxa de mortalidade. Aos 39 dias, 576 codornas foram remanejadas para gaiolas de postura, distribuídas em esquema fatorial $3 \times 2$, composto de três tipos de debicagem e dois tipos de bebedouro (taça e nipple), de modo que cada combinação foi avaliada com quatro repetições de 24 aves. A fase de produção teve início quando as aves atingiram 50\% de produção de ovos, aos 60 dias de idade. As codornas submetidas a debicagem por cauterização apresentaram menor ganho de peso e menor consumo de ração na fase de cria. O estresse pela dor com a debicagem por cauterização pode justificar não só o menor consumo e o menor ganho de peso, como também a maior mortalidade. Infere-se que este método, por ser mais demorado, tenha provocado mais dor e maior nível de estresse, piorando o desempenho das aves. A debicagem de 1/3 dos bicos cortados pode ter ocasionado estresse menos intenso às aves, não interferindo no desempenho. Não se observaram diferenças no desempenho das aves e na qualidade de ovos entre os tipos de bebedouro e métodos de debicagem utilizado na fase de produção. O método de debicagem por cauterização influencia o desempenho de codornas na fase de cria, mas, na fase de produção, assim como o tipo de bebedouro utilizado, não interfere no desempenho das aves nem na qualidade de ovos.

Palavras-chave: cauterização, coturnicutura, manejo, nipple, taça

\section{Beak trimming method and drinking system and a their effect on the performance and egg quality of japanese quails}

\begin{abstract}
A total of 672 one day old- female quails was allotted to a completely randomized experimental design, with three treatments (non-trimmed birds; 1/3 of the beak trimmed and cauterized beak), 8 replicates of 28 birds to evaluate the effect of beak trimming and drinking system on productive performance. The birds were beak trimmed at 21 days of age, and at day 35 the weight gain, feed intake, feed conversion and mortality were evaluated. At day 39, 576 quails were transfered to laying cages, and assigned to a 3x2 factorial arrangement, to evaluate three beak trimming methods and two drinking systems (cup and nipple) by using four replicates of 24 birds each. The production phase started when the birds reached $50 \%$ egg production, at 60 days of age. The quails submitted to beak trimming by cauterization showed smaller weight and lower feed intake during the initial period. Stress pain due to the cauterized beak can justify not only lower feed intake and lower weight gain, but also increased mortality. It can be inferred that once this method takes more time it has caused more pain and higher levels of stress, worsening the performance of birds. The trimmed to $1 / 3$ of the beaks cut can have caused stress to the birds less intense, without effect on performance. No differences on bird performance and egg quality were observed between drinking systems and beak trimming during the laying phase. In the initial phase, beak trimming system reduced performance, however, during the production phase, both drinking and beak trimming systems do not affect performance and egg quality of Japanese quails.
\end{abstract}

Key Words: cauterized beak, cup, management, nipple, quail rearing

\section{Introdução}

Codornas, assim como perus e galinhas, estão predispostas às reações de agressividade, como a bicagem e o canibalismo. De acordo com Cloutier et al. (2000), a debicagem é o principal método utilizado para coibir a bicagem de penas e o canibalismo na indústria avícola. A debicagem, quando bem realizada, reduz o desperdício de alimentos resultando em melhor conversão alimentar, melhora da eficiência alimentar e redução da mortalidade 
(Araújo et al., 2005). Estudos comprovam que a taxa de postura aumenta quando as aves são debicadas, o que pode ser resultado de menor mortalidade e do menor índice de ovos bicados, frutos de comportamento menos agressivo das aves.

A água, responsável pela maioria das funções do organismo, é o componente principal do sangue e dos fluidos extra e intracelular, é responsável pelo transporte, pela absorção e digestão de nutrientes, excreção de metabólitos, pelo equilíbrio da temperatura corporal, além de outras funções importantes (Leeson \& Summers, 2001). De acordo com Oliveira (2002), codornas bem debicadas apresentam melhor desempenho e acesso à água nos nipples e isso diminui a mortalidade e do comportamento agressivo das aves. Entretanto, Duncan et al. (1989) observaram redução da ingestão de água em bebedouros nipples por galinhas debicadas. Cunningham (1992) verificou a necessidade de mais pesquisas para melhor determinar os efeitos da debicagem sobre a ingestão de água em galinhas em diferentes condições ambientais e sistemas de bebedouro. Macari (1996) relatou um estudo realizado nos Estados Unidos, no qual se constatou que a postura de poedeiras diminuiu com a alteração do sistema, de bebedouro do tipo calha para o tipo nipple para aves alojadas em gaiolas. Gernat \& Adams (1990) afirmaram que selecionar um sistema de bebedouro para aves de postura pode ser difícil, pois depende de fatores como temperatura da água, número de bebedouros/ave, localização do bebedouro na gaiola e qualidade da água, que podem afetar a eficiência do sistema.

Devido à escassez de informações sobre a debicagem em codornas e sistemas de dessedentação, objetivou-se com este trabalho avaliar o efeito do tipo de debicagem e do tipo de bebedouro sobre o desempenho produtivo de codornas japonesas.

\section{Material e Métodos}

O desempenho e a qualidade de ovos de codornas foram avaliados em um experimento com duração de 172 dias. Foram adquiridas 672 codornas fêmeas japonesas (Coturnix coturnix japonica) com um dia de idade. As aves foram alojadas e recriadas em piso, onde receberam ração formulada para conter $20 \%$ de proteína bruta, $2.800 \mathrm{kcal}$ de energia metabolizável $/ \mathrm{kg}, 0,96 \%$ de cálcio e $0,45 \%$ de fósforo disponível até o início da produção de ovos. A ração foi fornecida à vontade e formulada à base de milho e farelo de soja, isoproteica e isocalórica, seguindo recomendações do NRC (1994), e a composição dos ingredientes utilizados seguiu a recomendação de Rostagno et al. (2000).
O programa de luz utilizado foi de 23 horas de luz na primeira semana e luz natural até a transferência das aves para as gaiolas, aos 40 dias. Adotou-se na fase inicial um delineamento inteiramente casualizado, com três tratamentos: aves não debicadas; debicadas levemente (com corte de 1/3 dos bicos) e debicadas através de cauterização (sem a realização do corte) e oito repetições, com 28 aves por repetição. As aves foram debicadas aos 21 dias de vida. Na coturnicultura comercial, a prática da debicagem aos 10 dias não é comum, como ocorre em poedeiras. Os produtores alegam que em codornas os bicos crescem rapidamente, portanto, há necessidade de outra debicagem quando as aves estão em fase de produção, o que ocasiona mortalidade elevada dos lotes, quedas na produção de ovos e demora no retorno da produção. Utilizou-se o debicador da marca Lyon 50/60 hertz, 70-210 watts. Para realização desse procedimento, a lâmina do aparelho Lyon, que é utilizada para realizar a debicagem das aves, foi retirada do aparelho e levada para um torneiro mecânico para a realização de um furo de 3,54 mm de diâmetro na parte inferior. Para a realização da debicagem, introduziram-se os bicos das aves no furo da lâmina, procedendo-se conjuntamente ao corte superior e inferior conjuntamente, seguido de cauterização com a lâmina quente, segundo as recomendações de Pizzolante et al. (2006). Na debicagem por cauterização, os bicos das aves foram medidos antes e depois do procedimento, com o auxílio de um paquímetro, e então encostados ligeiramente na lâmina quente para garantir a queima de 1/3 do bico.

Ao final do período de 35 dias, foram avaliados os seguintes parâmetros de desempenho da fase inicial: ganho de peso, consumo de ração, conversão alimentar e mortalidade.

Aos 39 dias de idade, 576 codornas foram transferidas do galpão de cria para o galpão de produção e distribuídas em 24 gaiolas metálicas com dimensões de $100 \mathrm{~cm}$ de comprimento, $34 \mathrm{~cm}$ de largura e $16 \mathrm{~cm}$ de altura, contendo quatro divisórias internas de $25 \mathrm{~cm}$, permitindo a acomodação de 24 codornas por gaiola (141,67 cm²/ave), conforme recomendações de Garcia et al. (1998) que observaram melhor desempenho em codornas alojadas em menor taxa de lotação. As gaiolas diferiam quanto ao tipo de bebedouro (taça ou nipple). O bebedouro tipo taça utilizado foi o copinho com placa da marca Plasson modelo 2206000 com vazão de 200 a $300 \mathrm{~cm}^{3} / \mathrm{min}$ (de 50 a $150 \mathrm{~cm}$ de coluna d’água) e o nipple, da marca Lubing modelo Combinipple $4078 \mathrm{com}$ vazão de $45 \mathrm{~cm}^{3} / \mathrm{min}$ (a $20 \mathrm{~cm}$ de coluna d'água e $3 \mathrm{~mm}$ de levantamento no pino inferior do nipple). 
Diariamente foram verificadas temperatura máxima e mínima e de bulbo seco e bulbo úmido. As médias de temperatura ambiente mínima e máxima no galpão durante o período de cria foram 18,5 e $28,7^{\circ} \mathrm{C}$, e 20,6 e $26,1^{\circ} \mathrm{C}$, respectivamente.

O delineamento experimental utilizado na fase de produção foi inteiramente casualizado em esquema fatorial $3 \times 2$, composto de três tipos de debicagem e dois tipos de bebedouro (taça e nipple), com quatro repetições de 24 aves cada. As aves foram submetidas durante todo o período experimental a idênticas condições de manejo (exceto o tipo de debicagem utilizado) e alimentação com água e ração à vontade. A dieta de postura foi formulada para conter $20 \%$ de proteína bruta, $2.900 \mathrm{kcal}$ de energia metabolizável $/ \mathrm{kg}, 2,5 \%$ de cálcio e $0,345 \%$ de fósforo disponível (Rostagno et al., 2000).

A coleta de dados da fase de produção teve início aos 60 dias, após a uniformização da postura. O desempenho das aves foi avaliado pelo peso dos ovos (g), pela produção de ovos (\%), massa de ovos (g), consumo de ração (g), conversão alimentar por dúzia de ovos e conversão alimentar por quilograma de ovos e taxa de mortalidade (\%). A qualidade dos ovos foi verificada ao final de cada período de 28 dias, retirando-se dois ovos de cada parcela, por três dias consecutivos, avaliando-se o peso dos ovos, gravidade específica, as porcentagens de gema, albúmem e casca. Os dados foram submetidos ao sistema de análise estatística com o auxilio do programa SISVAR (Ferreira, 1998) e as médias foram comparadas pelo teste Tukey a 5\% de probabilidade.

\section{Resultados e Discussão}

As aves submetidas à debicagem apenas por cauterização tiveram baixo desempenho no período de cria (Tabela 1). As codornas submetidas a este tipo de debicagem apresentaram menor ganho de peso se comparadas àquelas que não sofreram debicagem e às que tiveram apenas $1 / 3$ dos bicos debicados. O consumo de ração das aves não debicadas foi maior que o das aves com bicos apenas cauterizados e não diferiram estatisticamente das aves não debicadas ou que tiveram 1/3 dos bicos debicados. Não houve diferença significativa na taxa de mortalidade das codornas não debicadas e debicadas $1 / 3$, mas houve diferença quando comparados os resultados de mortalidade das aves não debicadas com as aves com bicos apenas cauterizados. Leandro et al. (2005) observaram em codornas submetidas à debicagem severa ou leve (1/2 e 1/3 dos bicos cortados) ganhos de peso inferiores $(\mathrm{p}<0,05)$ ao de aves não-debicadas. Os autores atribuíram o fato ao estresse causado pelo procedimento da debicagem, o qual provavelmente provoca dores no bico e prejudica a ingestão de alimento, conforme relatos de Kuo et al. (1991).

Lee \& Craig (1991) verificaram que galinhas poedeiras debicadas ao final da fase de recria apresentavam redução no ganho de peso corporal. As pesquisas de Moreno (1994) também mostraram que, durante o período de recria, galinhas poedeiras não debicadas, ou debicadas apenas uma vez, apresentaram peso vivo maior que o de aves debicadas três vezes. Bell (1996) reportou que galinhas não debicadas apresentaram maior peso corporal nas oito primeiras semanas de postura. Portanto, o menor ganho de peso observado nas codornas com bico queimado, após a debicagem, foi provavelmente uma resposta à redução na ingestão de alimento.

O estresse provocado pela dor e pelo sofrimento com a debicagem por cauterização pode justificar não só o menor consumo e o menor ganho de peso como a maior mortalidade das codornas. Acredita-se que, como este método é mais demorado que o da debicagem $1 / 3$, que corta e cauteriza rapidamente tenha provocado mais dor e consequentemente maior nível de estresse às codornas, piorando seu desempenho. O método de debicagem de $1 / 3$ dos bicos cortados pode ter ocasionado às aves estresse menos intenso, que não interferiu no seu desempenho.

Durante a fase de postura (produção), não houve interação significativa entre os fatores $(p>0,05)$. A análise de variância não indicou diferenças significativas $(p>0,05)$ em nenhum dos parâmetros de desempenho avaliados (Tabela 2).

Não houve diferenças $(\mathrm{p}>0,05)$ nos parâmetros de desempenho das aves entre os tipos de bebedouro. Esses

Tabela 1 - Desempenho de codornas japonesas de 1 a 35 dias de idade

\begin{tabular}{lccc}
\hline & \multicolumn{2}{c}{ Método de debicagem } \\
\cline { 2 - 4 } Variável & Sem debicagem & Debicagem $1 / 3$ & Cauterização \\
\hline Ganho de peso $(\mathrm{g})$ & $180,32 \mathrm{a}$ & $177,65 \mathrm{a}$ & $172,05 \mathrm{~b}$ \\
Consumo de ração $(\mathrm{g})$ & $538,18 \mathrm{a}$ & $533,75 \mathrm{ab}$ & 2,31 \\
Conversão alimentar $(\mathrm{g} / \mathrm{g})$ & 2,99 & 3,00 & 2,16 \\
Mortalidade $(\%)$ & $0,87 \mathrm{a}$ & $1,44 \mathrm{ab}$ & 3,02 \\
\hline
\end{tabular}

Médias com letras diferentes na mesma linha diferem significativamente $(\mathrm{P}<0,05)$ pelo teste Tukey. 
resultados corroboram relatos de Ramos et al. (1990) de que o uso de bebedouros nipple ou taça não influencia significativamente o consumo de ração, a produção de ovos e a conversão alimentar das poedeiras.

Embora não tenham observado diferenças significativas no consumo de ração, Togashi et al. (2008) constataram maior porcentagem de postura, massa de ovo e melhor conversão alimentar (kg ração/kg de ovo) entre poedeiras comerciais que receberam água em bebedouro nipple em comparação a aves criadas com bebedouro taça. De acordo com os autores, é possível que a maior produção de ovos e a melhor conversão alimentar observada para as aves criadas com bebedouro nipple estejam relacionadas à melhor qualidade da água, confirmada pela menor contaminação bacteriológica do nipple. Roush \& Boggan (1987), por exemplo, avaliaram o desempenho de poedeiras criadas em gaiolas abastecidas com bebedouro tipo nipple em comparação a vários modelos de bebedouros tipo taça e relataram que as aves abastecidas pelos modelos de sistemas tipo taça tiveram produção diária de ovos entre 5,5 e 8,8\% maior. Os piores resultados de conversão alimentar, peso corporal e mortalidade foram obtidos com os animais mantidos com bebedouro do tipo nipple.

As variáveis peso dos ovos, produção de ovos, massa de ovos, consumo de ração, conversão alimentar por dúzia de ovos produzidos, conversão alimentar por quilograma de ovos produzidos e mortalidade não foram influenciadas pelo tipo de debicagem $(\mathrm{p}<0,05)$, corroborando os resultados obtidos por Pizzolante et al. (2006), que não observaram diferenças entre codornas não debicadas e debicadas levemente (1/3 do bico); apenas observaram diferenças quando as codornas foram debicadas severamente ( $1 / 2$ do bico). Leandro et al. (2005) também não observaram diferença na taxa de postura e de conversão alimentar de codornas sob diferentes tipos de debicagem. O efeito de métodos de debicagem na produção de ovos de galinhas poedeiras foi investigado por Araújo et al. (2005) e os autores também não observaram diferenças na produção de ovos sendo encontrados resultados divergentes em relação ao consumo de ração apenas quando autores compararam debicagens severas e não debicagem (Araújo et al., 2000). Contrariamente, Sakomura et al. (1997) observaram menor produção de ovos em galinhas poedeiras debicadas quando comparadas às não debicadas, fato também observado por Van Niekerk et al. (1999).

Não houve diferenças significativas na taxa mortalidade $(\mathrm{p}>0,05)$ tanto para os métodos de debicagem como entre os tipos de bebedouro. Não houve interação significativa entre os fatores ( $p>0,05)$. A análise de variância não indicou diferenças $(p>0,05)$ entre os tipos de bebedouro e os métodos de debicagem para as características de qualidade de ovos avaliados (Tabela 3). Esses resultados corroboram os descritos por Pizzolante et al. (2007) e Leandro et al. (2005). Os tipos de debicagem avaliados não influenciaram $(\mathrm{p}>0,05)$ a qualidade da casca, gravidade específica, porcentagem de gema e de albúmem dos ovos das codornas japonesas. Pizzolante et al. (2007) observaram que codornas debicadas severamente (1/2 bico), diminuíram o consumo de ração, mas que este fator não influenciou a qualidade dos ovos.

Tabela 2 - Qualidade de ovos de codornas japonesas submetidas a debicagem por três métodos utilizando dois tipos de bebedouro

\begin{tabular}{|c|c|c|c|c|c|c|}
\hline \multirow[t]{2}{*}{ Parâmetro avaliado } & \multicolumn{2}{|c|}{ Tipo de bebedouro } & \multicolumn{4}{|c|}{ Métodos de debicagem } \\
\hline & Taça & Nipple & Não debicado & Debicagem $1 / 3$ do bico & Cauterização & $\mathrm{CV}, \%$ \\
\hline Peso dos ovos (g) & 12,47 & 12,53 & 12,51 & 12,49 & 12,49 & 1,94 \\
\hline Taxa de postura (\%) & 89,00 & 90,00 & 88,00 & 91,00 & 90,00 & 4,14 \\
\hline Massa de ovos (g) & 11,13 & 11,35 & 11,10 & 11,31 & 11,31 & 4,21 \\
\hline Consumo de ração (g/dia) & 30,76 & 30,75 & 30,97 & 30,63 & 30,67 & 2,07 \\
\hline Conversão alimentar (kg/dúzia) & 0,42 & 0,41 & 0,43 & 0,41 & 0,41 & 3,79 \\
\hline Conversão alimentar (kg/kg) & 2,82 & 2,76 & 2,83 & 2,75 & 2,77 & 4,22 \\
\hline Taxa de mortalidade (\%) & 2,36 & 2,39 & 1,75 & 3,07 & 2,30 & 45,39 \\
\hline
\end{tabular}

Médias seguidas de letras diferentes na mesma linha e em cada fator diferem $(\mathrm{p}<0,05)$ entre si pelo teste Tukey.

Tabela 3 - Qualidade de ovos de codornas japonesas submetidas a debicagem e mantidas com dois tipos de bebedouro

\begin{tabular}{|c|c|c|c|c|c|c|c|}
\hline \multirow[t]{2}{*}{ Parâmetro } & \multicolumn{2}{|c|}{ Tipo de bebedouro } & \multicolumn{5}{|c|}{ Métodos de debicagem } \\
\hline & Taça & Nipple & Não debicado & Debicado $1 / 3$ & Cauterização & $\mathrm{P}$ & $\mathrm{CV}, \%$ \\
\hline Gravidade específica $(\mathrm{g} / \mathrm{mL})$ & 1,076 & 1,077 & 1,076 & 1,077 & 1,076 & 0,78 & 0,46 \\
\hline Gema (\%) & 29,95 & 30,05 & 30,28 & 29,73 & 29,99 & 0,30 & 2,91 \\
\hline Albúmen (\%) & 62,68 & 62,48 & 62,25 & 62,85 & 62,65 & 0,36 & 1,31 \\
\hline Casca $(\%)$ & 7,36 & 7,47 & 7,47 & 7,42 & 7,35 & 0,48 & 3,74 \\
\hline
\end{tabular}

Médias seguidas de letras diferentes na mesma linha e em cada fator diferem $(p<0,05)$ entre si pelo teste Tukey. 
Togashi et al. (2008), comparando a utilização de bebedouros nipple e taça em galinhas poedeiras também afirmaram que nenhuma das características de qualidade dos ovos foi influenciada pelo tipo de bebedouro. Resultados semelhantes foram obtidos por Roush \& Mylet (1986) e Roush \& Boggan (1987), que verificaram que o tipo de bebedouro não influencia a porcentagem de casca e os valores de unidades Haugh dos ovos de galinhas poedeiras. Entretanto, Roush \& Boggan (1987) observaram que, quando utilizado bebedouro tipo taça, os valores de gravidade específica dos ovos foi menor em comparação aos obtidos com o bebedouro nipple.

\section{Conclusões}

O método de debicagem por cauterização influencia o desempenho de codornas na fase de cria, mas, na fase de produção, assim como o tipo de bebedouro utilizado, não interfere no desempenho das aves nem na qualidade de ovos.

\section{Referências}

ARAÚJO, L.F.; CAFÉ, M.B.; JUNQUEIRA, O.M. et al. Diferentes níveis de debicagem para frangas comerciais. Ars Veterinária, v.16, p.46-51, 2000.

ARAÚJO, L.F.; CAFÉ, M.B.; LEANDRO, N.S.M. et al. Performance of layer hens submitted or not to different methods of the beak trimming. Ciência Rural, v.35, n.1, p.169-173, 2005.

BELL, D. The merits of beak trimming. Intenational Poultry Production, v.4, n.4, p.34, 1996.

CLOUTIER, S.; NEWBERRY, R.C.; FORSTER, C.T. et al. Does pecking at inanimate stimuli predict cannibalistic behaviour in domestic fowl. Applied Animal Behaviour Science, v.66, p.119-133, 2000.

CUNNINGHAM, D.L. Beak trimming effects on performance, behavior and welfare of chickens: a review. Journal Applied Poultry Research, v.1, p.129-134, 1992.

DUNCAN, I.J.H.; SLEE, G.S.; SEAWRIGHT, E. et al. Behavioural consequences of partial beak amputation (beak trimming) in poultry. British Poultry Science, v.30, p.479-488, 1989.

GARCIA, E.A.; MENDES, A.A.; GONZALES, E. et al. Desempenho produtivo e econômico de codornas poedeiras alojadas sob diferentes taxas de lotação da gaiola. Boletim da Indústria Animal, v.55, n.2, p.185-188, 1998.

GERNAT, AG; ADAMS AW. Effect of number and location of nipple wateres and cage shape on the performance of caged layers. Poultry Science, v.69, n.12, p.2086-2091, 1990.

KUO, F.L.; CRAIG, J.V.; MUIR, W.M. Selection and beak trimming effects on behaviour, cannibalism, and short term production traits in White Leghorn pullets. Poultry Science, v.70, p.1057-1068, 1991.
LEANDRO, N.S.M.; VIEIRA, N.S.; MATOS, M.S. et al. Desempenho produtivo de codornas japonesas (Coturnix coturnix japonica) submetidas a diferentes densidades e tipos de debicagem. Acta Scientiarum Animal Sciences, v.27, n.1, p.129-135, 2005.

LEE, H.Y.; CRAIG, J.V. Beak trimming effects on behavior pattems, fearfülness, feathering, and mortality among three White Leghorn pullets in cage or floor pens. Poultry Science, v.70, n.2, p.211-212, 1991.

LESSON, S.; SUMMERS, J.D. Nutrition of the chicken. 4.ed. Guelph: University Books, 2001. 591p.

MORENO, S.Q. Efeito da debicagem e do enriquecimento ambiental no desempenho e na freqüência de bicadas por galinhas Hy-Line White mantidas em gaiolas. 1994. 52f. Monografia (Graduação em Zootecnia) - Faculdade de Ciências Agrária e Veterinárias de Jaboticabal/Universidade Estadual Paulista, Jaboticabal.

MACARI, M. Água na avicultura industrial. Jaboticabal: FUNEP, 1996. 128p.

NATIONAL RESEARCH COUNCIL - NRC. Nutrient requirements of poultry. 8.rev.ed. Washington, D.C.: National Academy Press, 1994. 157p.

OLIVEIRA, B.L. Manejo racional e produtividade das codornas. In: SIMPÓSIO INTERNACIONAL DE COTURNICULTURA, 1., 2002, Lavras. Anais... Lavras: Universidade Federal de Lavras, 2002. p.77-95.

PIZZOLANTE, C.C.; GARCIA, E.A.; SALDANHA, E.S.P.B. et al. Break trimming methods and their effect on the performance of japanese quails pullets (Coturnix japonica). Revista Brasileira de Ciência Avícola, v.8, n.4, p.213-216, 2006.

PIZZOLANTE, C.C.; GARCIA, E.A.; SALDANHA, E.S.P.B. et al. Break trimming methods and their effect on the performance and egg quality of Japanese quails (Coturnix japonica) during lay. Revista Brasileira de Ciência Avícola, v.9, n.1, p.7-21, 2007.

RAMOS, N.C.; GERNAT, A.G.; ADAMS, W. Effects of cage, shape, age at housing and types of rearing and layer waterers on the productivity of layers. Poultry Science, v.69, p.217-223, 1990

ROSTAGNO, H.S.; ALBINO, L.F.T.; DONIZETE, J.L. et al. Tabelas brasileiras para aves e suínos: composição de alimentos e exigências nutricionais. Viçosa, MG: Universidade Federal de Viçosa, 2000. 141p.

ROUSH, W.B.; BOGGAN, G.D. Effect of watering devices on performance during pullet-rearing and cage-laying phases of Single Comb White Leghorn hens. Poultry Science, v.66, p.1431-1436, 1987.

ROUSH, W.B.; MYLET, M. Effect of water softening watering devices, and dietary salt level on the performance of caged Single Comb White Leghorn laying hens. Poultry Science, v.65, p.1866-1871, 1986.

SAKOMURA, N.K.; MORENO, S.Q.; PARANHOS DA COSTA, M.J.R. et al. Efeito da debicagem e do enriquecimento ambiental no desempenho de galinhas poedeiras. Ars Veterinária, v.13, p.59-67, 1997.

TOGASHI, C.K.; ANGELA, H.L.; FREITAS, E.R. et al. Efeitos do tipo de bebedouro sobre a qualidade da água e o desempenho e a qualidade dos ovos de poedeiras comerciais. Revista Brasileira de Zootecnia, v.37, n.8, p.1450-1455, 2008.

VAN NIEKERK, G.C.M.; REUVEKAMP, B.F.J.; VAN EMOUS, R.E. Advantages and disadvantages of beak trimming of laying hens. World Poultry, v.15, n.11, p.25-28, 1999. 